\title{
Pengaruh Intellectual Capital Terhadap Return Saham Dengan Profitabilitas Sebagai Variabel Intervening
}

\author{
Rizki Fazrin ${ }^{1}$ \\ Fakultas Ekonomi dan Bisnis \\ Universitas Mataram, Indonesia. \\ Email: rizkifazrin054@gmail.com

\section{Nyoman Nugraha Ardana Putra ${ }^{3}$ \\ Fakultas Ekonomi dan Bisnis \\ Universitas Mataram, Indonesia}

\author{
Hermanto ${ }^{2}$ \\ Fakultas Ekonomi dan Bisnis \\ Universitas Mataram, Indonesia.
}

\begin{abstract}
ABSTRAK
Penelitian bertujuan menganalisis pengaruh tidak langsung intellectual capital terhadap Return Saham melalui Profitabilitas. Sampel penelitian adalah Perusahaan perbankan yang terdaftar di Bursa Efek Indonesia periode 2013-2017. Metode penentuan sampel ditentukan dengan purposive sampling diperoleh 145 sampel. Alat analisis data menggunakan path analysis. Hasil penelitian menunjukan intellectual capital tidak berpengaruh positif terhadap return saham melalui profitabilitas sebagai variabel intervening. Implikasi penelitian sebagai bahan pertimbangan bagi regulator di bidang akuntansi mengenai pentingnya informasi intellectual capital sehingga regulasi perlu dibuat mengenai cara mengukur, mengakui dan melaporkanya. Dibuat dengan tujuan agar bisa dipergunakan oleh investor dalam mengambil keputusan dalam melakukan investasi.
\end{abstract}

Kata Kunci : Intellectual Capital, Return Saham, Profitabilitas.

\section{The Effect Of Intellectual Capital On Stock Return With Profitability as an Intervening Variable}

\begin{abstract}
The study aims to analyze the indirect influence of Intellectual Capital and Stock Return through profitability. Banking companies listed in Indonesia Stock Exchange 2013-2017 period. Samples were determined by purposive sampling obtained 145 samples. Data analysis tools using Path Analysis. Intellectual capital research findings showed no positive effect on stock returns over profitability as an intervening variable. As the research implications for consideration by the regulator in the field of accounting on the importance of intellectual capital information so that the regulation needs to be made on how to measure, recognize and report it.
\end{abstract}

Keywords: Intellectual Capital, Stock Return, Profitability.

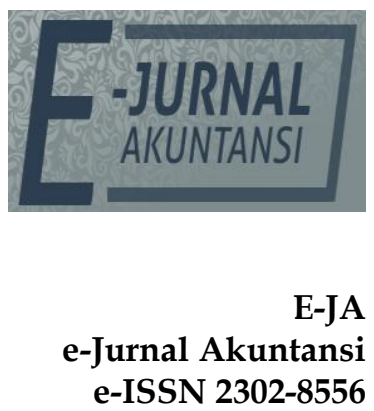

Vol. 29 No. 1 Denpasar, Oktober 2019

Hal. 145-157

Artikel masuk: 13 Agustus 2019

Tanggal diterima: 23 September 2019 


\section{PENDAHULUAN}

Globalisasi dan pesatnya persaingan bisnis membuat inovasi bisnis dan persaingan bisnis semakin meningkat. Para pelaku usaha dituntut untuk memiliki daya saing agar dapat menjaga eksistensi dan keberlangsungan usahanya. Hal ini menyebabkan banyak perusahaan mengubah cara bisnisnya, sehingga secara tidak langsung menyebabkan perataan ekonomi suatu negara. Persaingan usaha bisnis yang semakin kuat di pasar global menutut perusahaanperusahaan untuk melakukan berbagai inovasi bisnis dan strategi untuk memenangkan persaingan. Cara yang dilakukan oleh perusahaan untuk mengubah cara bisnis yang sebelumnya didasarkan pada tenaga kerja menuju pengetahuan, sehingga karakteristik utama perusahaan adalah berdasarkan ilmu pengetahuan yang dimiliki oleh setiap karyawan perusahaan tersebut. Selain itu persaingan membuat setiap perusahaan semakin meningkatkan kinerja karyawan agar tujuannya dapat tercapai.

Menggunakan ilmu pengetahuan dan teknologi yang dimiliki oleh setiap karyawan perusahaan maka akan dapat diperoleh bagaimana perusahaan menghadapi persaingan bisnis dengan menggunakan sumber daya lainnya secara ekonomis dan efisien yang nantinya akan memberikan keunggulan pada perusahaan dalam bersaing. Bersama adanya perubahan lingkungan bisnis yaitu bisnis berdasarkan pengetahuan, para bisnis mulai menyadari bahwa kemampuan bersaing tidak hanya terletak pada kepemilikan asset berwujud, tetapi yang terpenting adalah aktiva tidak berwujud yang dimiliki oleh perusahaan, dalam hal ini adalah modal intelektual.

Fenomena modal intelektual mulai berkembang terutama setelah munculnya Pernyataan Standar Akuntanis Keuangan (PSAK) No. 19 (revisi 2000) tentang aset tidak berwujud. Menurut PSAK No. 19, asset tidak berwujud adalah aktiva non-moneter yang dapat diidentifikasikan dan tidak dapat memiliki wujud fisik serta dimiliki untuk digunakan dalam menghasilkan atau menyerahkan barang atau jasa, disewakan kepada pihak lainnya, atau untuk tujuan administrasi (Ikatan Akuntansi Indonesia, 2002). perusahaan-perusahaan yang ada di Indonesia belum menaruh banyak perhatian terhadap modal intelektual. Perusahaan-perusahaan di Indonesia cenderung menggunakan bisnis yang didasarkan pada tenaga kerja dalam membangun bisnisnya, sehingga produk yang didapat masih jauh dari kandungan teknologi (Ulum, 2009).

Penelitian modal intelektual dengan tema berbeda, mencoba untuk menghubungkan modal intelektual dengan return saham. Penelitian ini pernah dilakukan oleh (Prastiwi \& Muna, 2014) yang mengatakan bahwa modal intelektual berpengaruh positif terhadap return saham, yang artinya modal manusia adalah salah satu komponen modal intelektual yang berupa kemampuan, keterampilan, dan pengetahuan yang dimiliki seseorang yang digunakan perusahaan untuk menghasilkan layanan profesional. Dengan demikian sumber daya yang unggul dan berkualitas, sehingga perusahaan dapat mengeksploitasi secara maksimal kemampuan karyawannya dengan baik yang dimiliki oleh perusahan. Hal tersebut akan meningkatkan nilai tambah bagi perusahaan, sehingga meningkatkan kinerja karyawan perusahaan. diharapkan mampu meningkatkan kepercayaan stakeholder terhadap going concern 
perusahaan sehingga return saham turut meningkat. Hasil penelitian tersebut berbeda dengan penelitian yang dilakukan oleh (Aprilia \& Isbanah, 2018) dan (Marlinda, 2018) yang mengatakan bahwa modal intelektual tidak berpengaruh terhadap return saham. Penelitian mengenai pengaruh modal intelektual terhadap Profitabilitas sebagai variabel intervening pernah dilakukan oleh (Prastiwi \& Muna, 2014), (Aprilia \& Isbanah, 2018), dan (Marlinda, 2018) mengatakan bahwa modal intelektual berpengaruh positif terhadap Profitabiltas sebagai variabel intervening.

Penelitian ini juga memiliki keterbaruan yaitu dalam hal pengukuran variabel intervening yang digunakan. Variabel intervening yang digunakan oleh penelitian terdahulu antara lain (Prastiwi \& Muna, 2014), (Aprilia \& Isbanah, 2018) dan (Marlinda, 2018) adalah Return On Equity dan Earning Per Share, sedangkan variabel intervening yang digunakan peneliti saat ini menggunakan Return On Asset (ROA). Alasan menggunakan Return On Asset adalah perusahaan dapat memberikan gambaran kepada investor mengenai bagaimana perusahaan dapat mengelola uang yang diinvestasikan pada salah satu perusahaan dalam laba bersih. Terpilihnya perusahaan sektor perbankan sebagai objek penelitian ini karna pada umumnya, (1) sektor perbankan adalah sector yang masih mendistribusikan dananya pada aset keuangan dalam Bursa Efek Indonesia (Jayanti \& Binastuti, 2017), (2) sektor perbankan juga dikategorikan sebagai sektor industri yang berbasis kecerdasan atau pengetahuan yang berinovasi dalam bentuk jasa dan produk serta fleksbelitas dan pengetahuan yang merupakan aspek penting dalam menentukan kesuksesan perusahaan menjalani bisnis yang telah dilakukan sehingga akan sulit menilai pengaruh modal intelektual terhadap return saham perusahaan. Penelitian ini dilakukan untuk menguji Pengaruh Intellectual Capital terhadap Return Saham dengan Profitabilitas Sebagai variabel Intervening pada Perusahaan Perbankan yang terdaftar di Bursa Efek Indonesia periode 2013- 2017.

Berdasarkan latar belakang diatas, rumusan masalah dalam penelitian ini adalah sebagai berikut: 1. Apakah Intellectual Capital berpengaruh terhadap Profitabilitas? 2. Apakah Intellectual Capital berpengaruh terhadap Return Saham? 3. Apakah Profitabilitas berpengaruh terhadap Return Saham? 4. Apakah Intellectual Capital berpengaruh secara tidak langsung terhadap Return Saham melalui Profitabilitas? Berdasarkan rumusan masalah diatas, maka tujuan dari penelitian ini adalah sebagai berikut: Untuk menganalisis pengaruh Intellectual Capital terhadap Profitabilitas, Return Saham dan pengaruh tidak langsung Intellectual Capital terhadap Return Saham melalui Profitabilitas.

Teori sumber daya mengganggap bahwa pengetahuan sebagai sumber daya yang paling signifikan dan strategis dari perusahaan. Pengidenfikasian sumber daya yang dimiliki oleh perusahaan dapat menciptakan nilai tambah bagi perusahaan dalam mengambil keuntungan kesempatan, dan menghadapi ancaman sehingga perusahaan memiliki keunggulan kompetitif yang berbeda dengan perusahaan lain, tidak mudah ditiru, dan tidak tergantikan. Menurut Pearce dan Robinson dalam (Prastiwi \& Muna, 2014), asumsi yang mendasari teori berdasarkan sumber daya adalah perusahaan berbeda secara fundamental karena setiap perusahaan memiliki kumpulan sumber daya yang unik berupa asset berwujud dan tidak berwujud serta kapabilitas organisasional untuk 
memanfaatkan asset tersebut. Menurut Deegan (2004) dalam (Indrajaya, n.d.) (2015) bidang etika berpendapat bahwa stakeholder memiliki hak untuk diperlakukan secara adil oleh perusahaan dan manajer harus mengelola oragnisasi untuk keuntungan seluruh stakeholder. Aspek etika akan terpenuhui jika manajer perusahaan mampu mengelola dan memanfaatkan dalam proses penciptaan nilai perusahaan sehingga dengan adanya penciptaan nilai maka investor akan mendapatkan informasi yang dia butuhkan dalam mengambil keputusan atau rencana yang akan datang untuk menghasilkan keuntungan yang di dapat (Ulum, 2013) (Ulum, 2009:6).

Teori sumber daya menjelaska bahwa the company's yang memanfaatkan mengelola resource based intellectual karyawan perusahaan yang bagus dapat menggapai kelebihan bersaing dan value added. Atas dasar kelebihan bersaing dan value added meningkat maka investor akan memberikan fee untuk karyawan perusahaan deengan menanakan modal lebih tingi, (Prastiwi \& Muna, 2014). Bedasarkan stakeholder dan resource based theory bahwa intellectual capital memiliki pengaruuh positip terhdap profitability. pengaruh modal intelektual terhaadap Profitability pernah dilakukan oleh (Prastiwi \& Muna, 2014), (Aprilia \& Isbanah, 2018), (Dr. Yuskar1E Dhia Novita, SE, n.d.) dan (Marlinda, 2018) mengatakan bahwa intellectual captal memiliki pengaruh positif terhadap profitabilitas.

$\mathrm{H}_{1}$ : Intellectual Capital berpengaruh positif terhadap profitabilitas.

Menurut (Prastiwi \& Muna, 2014) Berdasaarkan Signalling theori, kandungan informasi pada pengungkapan suuatu informaasi dapt menjadii siinyal bagi investo dan pihak potensia lainya dalam mengambil keputusan ekonomi. Dengan demikian, pengungkapan intellectual capital mampu menjadi sinyal bagi investor. Penelitian ini mendukung hasil penelitian yang dilakukan oleh (Prastiwi \& Muna, 2014), Modal Intelektual memiliki pengaruh positif terhadap Stock Return

$\mathrm{H}_{2}$ : Intellectual Capital berpengaruh positif terhadap Return Saham.

Investor lebih memandang atau melihat analisis fundamental perusahaan untuk menanamkan sahamnya pada perusahaan. Investor dalam mengambil keputusan atau perencanaan lebih mendahulukan analisis fundamental perusahaan dibandingkan dengan melihat analisis teknikal atau yang terjadi langsung di pasar modal sehingga investor yang pertama kali dilihat sebelum menanmkan dananya atau melakukann investasi investor akan melihat analisis fundamental dan laporan keuangan yang terjadi lima tahun terakhir. Serta investor akan melihat kinerja karyawan perusahaan dalam mengambil keputusahan untuk mendapat keuntungan yang akan diperoleh setelah melakukan investasi pada perusahaan tersebut dan dengan adanya kinerja perusahaan yang baik akan menyebabkan profitabilitan meningkat, dengan meningkatnya perusahaan otomatis juga return atau laba yang akan didapat akan tinggi. Hasil penelitian ini mendukung yang dilakukan oleh (Prastiwi \& Muna, 2014) yanng mengattakan bawa profitabilitas memilki pengarruh positif terhadaap retern sahaam.

$\mathrm{H}_{3}$ : Profitabilitas berpengaruh positif terhadap return saham.

Investor melihat kinerja karyawan industri dalaam mengambl keputtusan untuki berinvestsi pada perusahan. Penanam modal lebih melihat analsisi 
fundamental perusahaan dibandingkan analisis teknikal. Apabila fundamental perusahaan baik maka investor akan melakukan investasi pada company's tersebut sehingga secara tidak langsung akan efek pada return saham perusahaan dan investor akan mendapatkan keuntungan yang didapat dari kenaikan profitabilitas yang diakibatkan oleh kenaikan fundamental perusahaan tersebut. Penelitiaan in menduukung hasil penelitian yang dilakkukan oleh (Prastiwi \& Muna, 2014) Intelectual captal memliki pengaruh positif seecara tidk langssung terhadap stock return melalui profitability.

H4: Intellectual Capital berpengaruh positif secara tidak langsung terhadap Return Saham melalui Profitabilitas.

Secara sistematis rerangka konseptual penelitian ini dapat dilihat pada Gambar 1 sebagai berikut:

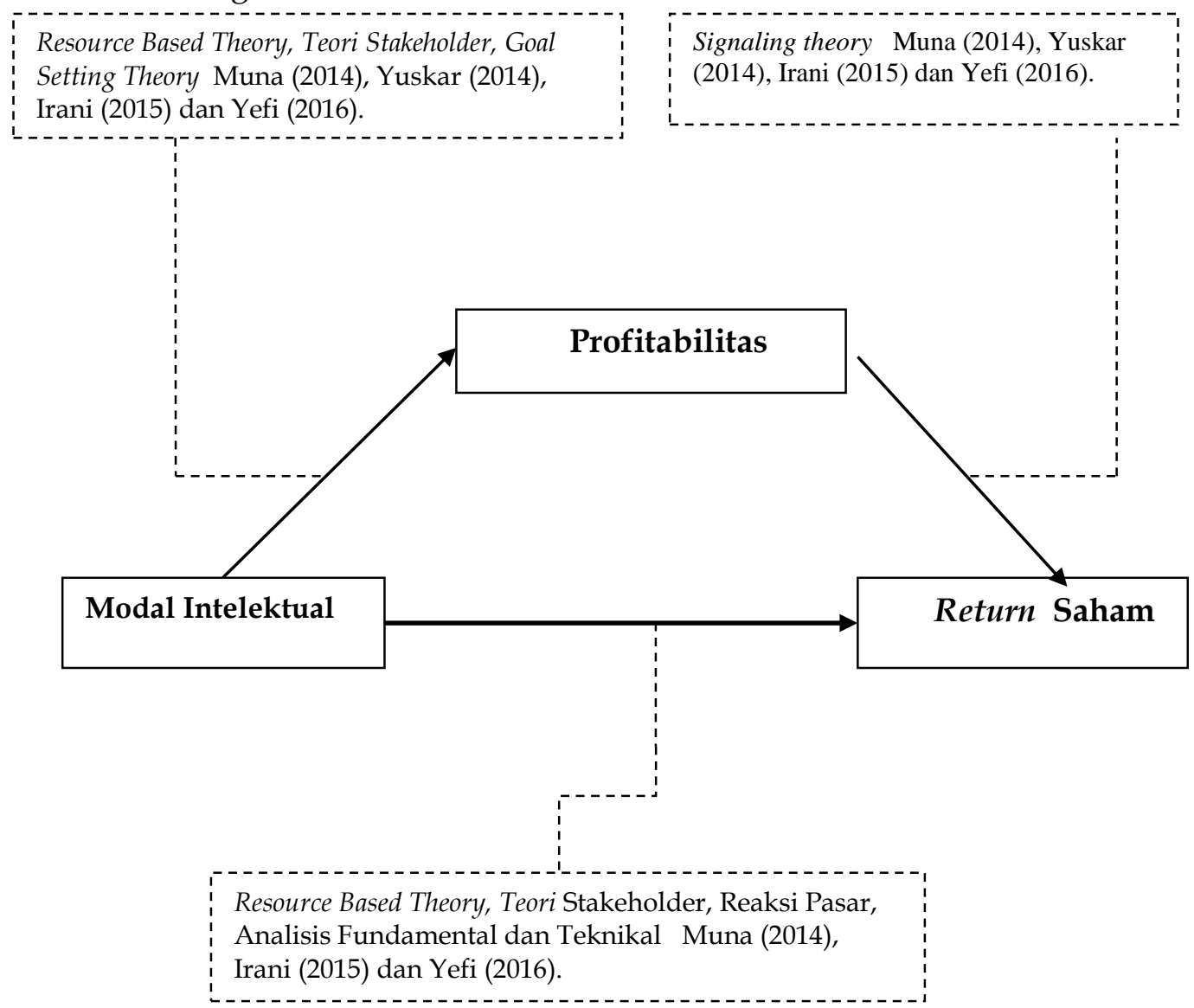

Gambar 1. Kerangka Konseptual Penelitian

Sumber: Data Penelitian, 2019

\section{METODE PENELITIAN}

Jenis penelitiaan yang diguanakan adalah penelitaian asosiatiif deengan pendektan kuanttatif. Penelitian asossiatif adalah penelitian yang bertjuan untk mengetahui pengaruh dua variabel atau lebih. Objeek penelitiaan di perusahan perbnakan yang terdaptar di Bursa Efek Indonesia Perirode 2013-2017.

Menurut (Sugiyono, 2012:61) populasi merupakan subjek atau objek yang digunakan untuk melakuikan penelitian yang akan diambik kesimpulan. 
Populasi dalam penelitiian in adlah perusahan perbankan yanng terrdaftar di Burrsa efeek Indionesia yang terdaftar di Bursa Efek Indonesia periode 20132017. Sedangkan sampel adalh bagian dari populasi. Tehknik samplling yang digunakan dalm pengmbilan sample adalaah Purpossive samplling.

\section{Tabel 1. Perhitungan Sampel}

\begin{tabular}{llc}
\hline No & Kriteria Pemilihan Sampel & Jumlah \\
\hline 1 & $\begin{array}{l}\text { Perusahaan Perbankan yang terdaftar di Bursa Efek Indonesia } \\
\text { selama } 5 \text { tahun berturut- turut dari tahun 2013-2017. }\end{array}$ & 43 \\
2 & $\begin{array}{l}\text { Perusahaan Perbankan yang tidak melaporkan Laporan } \\
\text { keuangan secara lengkap dari tahun 2013-2017. }\end{array}$ & $(10)$ \\
3 & $\begin{array}{l}\text { Perusahaan Perbankan yang memiliki laba bersih negatif dari } \\
\text { tahun 2013-2017. }\end{array}$ & $(4)$ \\
& Perusahaan yang memenuhui kriteria sampel & 29 \\
& Jumlah sampel $(29 \times 5$ tahun $)$ & 145 \\
\hline
\end{tabular}

Sumber: Data Penelitian, 2019

Variabel bebas dalam penelitian ini adalah Intellectual Capital. Menurut (Jayanti \& Binastuti, 2017), modal intelektual adalah sumber daya yang dimiliki perusahaan berupa pengetahuan, keahlian, informasi dan kemampuan yang dimiliki oleh setiap individu karyawan perusahaan yang menjadi keunggulan dalam bersaing untuk menciptakan value added bagi perusahaan tersebut. Jumlah yang dihasilkan dari modal intelektual adalah modal manusia, modal structural dan modal pelanggan. kombinasi dari ketiga nilai tambah tersebut disimbolkan dengan nama VAICTM yang dikembangkan oleh Pulic. Variabel terikat dalam penelitian ini adalah Return saham. Return saham diukur dengan Harga saham pada periode $t$ (harga investasi sekarang) dikurangi Harga saham sebelum periode $\mathrm{t}$ (harga investasi periode lalu) ditambah Dividen yang dibagikan sekarang dibagi Harga saham sebelum periode $t$ (harga investasi periode lalu) (Aprilia \& Isbanah, 2018). Sedangkan variabel intervening dalam penelitian ini adalah Return On Asset (ROA). Return On Asset diukur dengan membandingkan Laba Bersih Sebelum Pajak dengan Total Asset (Sartono, 2012).

Teknik analisis yang digunakan dalam penelitian ini adalah path analsysis. untuk menganalisis pola hubungan antar variabel dengan tujuan untuk mengetahui pengaruh tidak langsung seperangkat variabel bebas terhadap variabel terikat yang dimediasi oleh variabel intervening. Data yang akan diolah terlebih dahulu harus bebas dari uji asumsi klasik. pengujian asumsi klasik dilakukan agar nilai parameter model penduga yang digunakan dinyatakan valid. Pengujian asumsi klasik yang harus dipenuhui antara lain uji normalitas, multikolinearitas, autokorelasi, dan heteroskedastisitas. Model Persamaan penelitian ini sebagai berikut:

ROA $=a+\beta_{1}$ VAICTM + e1

RS $\quad=\alpha+\beta_{2}$ VAICTM + e2

RS

$$
=a+\beta_{3} \mathrm{VAIC}^{\mathrm{TM}}+\beta_{4} \mathrm{ROA}+\mathrm{e} 3 .
$$

Keterangan:

Profitabilitas di proksikan oleh ROA 
Modal Intelektual di proksikan VAICTM

Return saham di proksikan RS

$\beta_{1} \quad$ : Koefesien jalur ROA dan VAIC ${ }^{\mathrm{TM}}$

$\beta_{2} \quad$ : Koefesien jalur RS dan VAICTM

$\beta_{3} \quad$ : Koefesien jalur RS dan ROA

e1 : residual profitabilitas

e2 : residual Return saham

\section{HASIL DAN PEMBAHASAN}

Uji Asuumsi Klasik yaang digunakan dalam penelitian ini adalah uji normaliitas, uji autokrelasi, uji multiklinearitas, dan uji heteroskdastisitas. Uji normalitas bertujuan menguji apakah dalam model regresi, variabel pengganggu atau residual memiliki distribusi normal. Uji normalitas dalam penelitian ini secara statistik menggunakan grafik P-P Plot (probability plot). Pada prinsipnya normalitas dapat dideteksi dengan melihat penyebaran data (titik) pada sumbu diagonal dari grafik atau dengan melihat histogram dari residualnya.

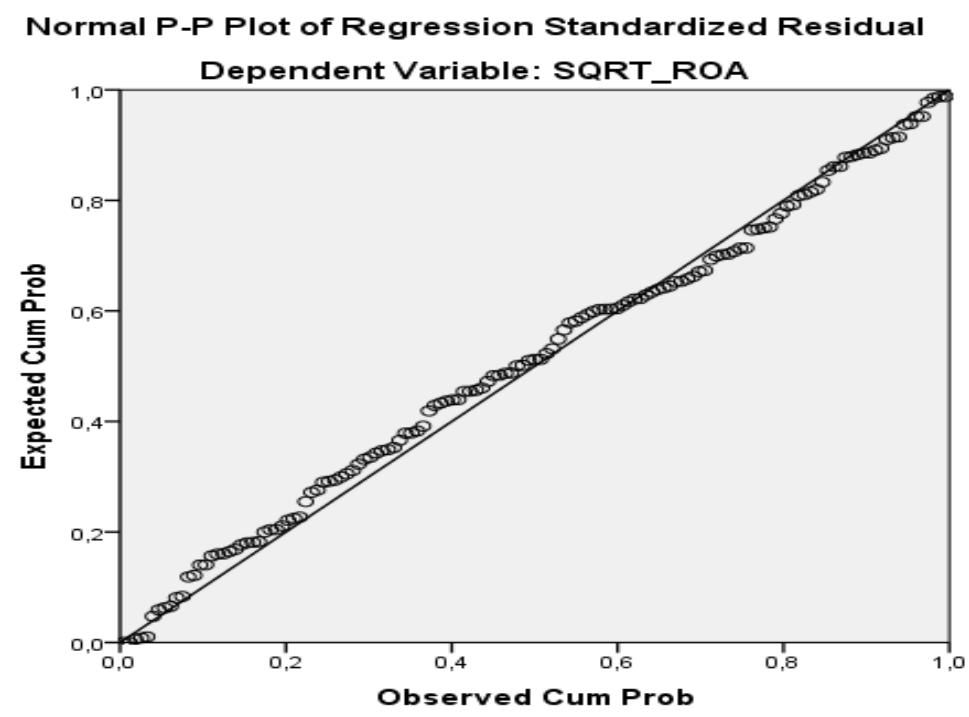

Gambar 2. Hasil Uji Normalitas

Sumber: Data Penelitian, 2019

Berdasarkan Gambar 2 menunjukan bahwa data menyebar disekitar garis diagonal dan mengikuti arah garis diagonal atau grafik histogramnya menunjukan pola distribusi normal, maka model regresi memenuhi asumsi normalitas. Uji autokorelasi bertujuan menguji apakah dalam model regresi linier ada korelasi antara kesalahan pengganggu pada periode $t$ dengan kesalahan pengganggu pada periode t-1 (sebelumnya). Cara yang dapat digunakan untuk mendeteksi ada atau tidaknya autokorelasi dengan uji durbinwatson, yaitu dengan membandingkan nilai DW hasil regresi dengan dL dan dU dari tabel durbin watson (Ghozali, 2011). 
Tabel 2. Hasil Uji Autokorelasi

\begin{tabular}{crrrcc}
\hline Model & $\mathrm{R}$ & R Square & Adjusted R Square & $\begin{array}{c}\text { Std. Error of the } \\
\text { Estimate }\end{array}$ & Durbin-Watson \\
\hline 1 &, $479 \mathrm{a}$ &, 230 &, 224 & 3,68448 & 1,773
\end{tabular}

a. Predictors: (Constant), SQRT_IC

b. Dependent Variable: SQRT_ROA

Sumber : Data Penelitian, 2019

Berdasarkan hasil pengujian dengan SPSS 21, dapat dilihat dalam tabel 2 di atas yang menunjukkan bahwa nilai durbin watson sebesar 1,773 dengan $\mathrm{n}=$ 145 dan $\mathrm{k}=1$, maka didapat nilai dL dan dU masing-masing sebesar 1,714 dan 1,742. Angka durbin watson ini berada di antara du $<\mathrm{dw}<4$-du yaitu $1,742<$ $1,773<2,258$ sehingga dapat disimpulkan bahwa tidak terjadi autokorelasi. Uji Heteroskedastisitas bertujuan menguji apakah dalam model regresi terjadi ketidaksamaan variance dari residual satu pengamatan ke pengamatan yang lain. untuk melihat ada tidaknya masalah heteroskedastisitas dapat juga dilakukan dengan uji glejser. Uji ini dilakukan dengan membandingkan nilai sig dari masing-masing variabel independen. Apabila sig $>0,05$, maka dapat disimpulkan tidak terjadi masalah heteroskedastisitas.

Tabel 3. Hasil Uji Heteroskedastisitas

\begin{tabular}{|c|c|c|c|c|c|c|}
\hline & \multirow[t]{2}{*}{ Model } & Unstandarc & Coefficients & Standardized & \multirow[t]{2}{*}{$t$} & \multirow[t]{2}{*}{ Sig. } \\
\hline & & $\mathrm{B}$ & Std. Error & Beta & & \\
\hline \multirow{3}{*}{1} & (Constant) & ,475 & ,914 & &, 520 & 604 \\
\hline & SQRT_IC & 1,255 & ,487 & 213 & 2,574 & ,071 \\
\hline & \multicolumn{6}{|c|}{ a. Dependent Variable: ABS_RES_1 } \\
\hline
\end{tabular}

Sumber : Data Penelitian, 2019

Hasil uji heteroskedastisitas menggunakan uji glejser dari tabel 3 menunjukkan nilai sig variabel Intellectual Capital (IC) sebesar 0,071 lebih besar dari 0,05 maka dapat disimpulkan bahwa dalam penelitian ini tidak terjadi masalah heteroskedastisitas.

Tabel 4. Hasil Uji Statistik Modal Intelektual Terhadap Profitabilitas

\begin{tabular}{lllllll}
\hline Model & \multicolumn{2}{l}{$\begin{array}{l}\text { Unstandardized } \\
\text { Coefecients }\end{array}$} & $\begin{array}{l}\text { Standardized } \\
\text { Coefecients }\end{array}$ & \multirow{2}{*}{ Sig. } \\
\cline { 3 - 4 } & & B & Std. Error & Beta & & \\
\cline { 3 - 4 } 1 & (Costanta) & 3,823 & 1,433 & & 2,669 & 0,009 \\
& SQRT_IC & 4,92 & 0,764 & 0,479 & 6,438 & 0,000 \\
\hline
\end{tabular}

a. Dependent Variable: SQRT_ROA

Sumber : Data Penelitian, 2019

Berdasarrkan Tabel 4 nilai koefesien jalur modal intelektual (IC) terhadap profitabilitas sebesar 0,479. Nilai koefesien jalur sebesar 0,479 menunjukan bahwa koefesien jalur IC terhadap ROA tidak sama dengan nol $(p \neq 0)$. Selanjutnya berdasarkan tabel 2 bawa nilai $t_{\text {hitung }}$ sebesar 6,438 sedangkan $t_{\text {tabel }}$ dengan $(\mathrm{N}=145, \mathrm{k}=1, \mathrm{a}=0,05)$ diketahui sebesar 1,6554 . Bedasarkan hasil uji $t_{\text {hitung }}$ dengan $t_{\text {tabel }}$ diperoleh $t_{\text {hitung }}>$ nilai $t_{\text {tabel }}$ yaitu 6,438 $>1,6554$ sig $0,000<0,05$. kesimpulan modal intelektual memilki pengaruh positif terhaadap profitability pada perusahaaan perbangkan yang terdaptar di Bursa efek Indonesiaa perioode 2013-2017. 
Tabel 5. Hasil Uji Statistik Modal Intelektual terhadap Return Saham

\begin{tabular}{ccccccc}
\hline \multirow{2}{*}{ Model } & \multicolumn{2}{c}{$\begin{array}{c}\text { Unstandardized } \\
\text { Coefecients }\end{array}$} & $\begin{array}{c}\text { Standardized } \\
\text { Coefecients }\end{array}$ & \multirow{2}{*}{ S } & Sig \\
\cline { 3 - 4 } & & B & Std Error & Beta & & \\
\hline \multirow{2}{*}{1} & (Costanta) & 5,787 & 1,714 & & 3,377 & 0,001 \\
& SQRT_IC & $-0,13$ & 0,893 & $-0,016$ & $-0,145$ & 0,885 \\
\hline
\end{tabular}

a. Dependen Variabel:SQRT_RS

Sumber : Data Penelitian, 2019

Berdasarrkan Tabel 5. diperoleh nilai koefesien jalur pengaruh Modal Intelektual (IC) terhadaap stock return sebesarr -0,016 dan nilaii thitung sebesaar 0,145 , sementara nilaai dari $t_{\text {tabel }}$ dengan dengan $(\mathrm{N}=145, \mathrm{k}=1, \mathrm{a}=0,05)$ sebesar 1,6554 . Berdasarkan hasil uji $t_{\text {hitung }}$ dan $t_{\text {tabel }}$ diperoleh $t_{\text {hitung }}<$ nilai $t_{\text {tabel }}$ yaitu $0,145<1,6554$. Nilai koefesien jalur sebesar $-0,016$ menunjukan bahwa koefesien jalur pengaaruh intelectual captal (IC) terhadap stock retern tidak sama deengan nol. intellectual capital (IC) tidak mampu menjelaskan variabel stock return paada perusahan Perbnkan yang terdftar di Bursa Efeek Indonesia periode 2013-2017.

Tabel 6. Uji Statistik Modal Intelektual dan Profitabilitas terhadap Retern Sahaam

\begin{tabular}{|c|c|c|c|c|c|c|}
\hline \multirow{2}{*}{\multicolumn{2}{|c|}{ Model }} & \multicolumn{2}{|c|}{$\begin{array}{l}\text { Unstadardized } \\
\text { Coefecients }\end{array}$} & $\begin{array}{c}\text { Standardized } \\
\text { Coefecients }\end{array}$ & \multirow[t]{2}{*}{$\mathrm{t}$} & \multirow[t]{2}{*}{ Sig. } \\
\hline & & B & Std. Error & Beta & & \\
\hline \multirow{3}{*}{1} & (Costanta) & 6,231 & 1,697 & & 3,671 & 0,000 \\
\hline & SQRT_IC & $-0,744$ & 1,079 & $-0,093$ & $-0,689$ & 0,493 \\
\hline & $\begin{array}{l}\text { SQRT_RO } \\
\text { A }\end{array}$ & 0,045 & 0,114 & 0,054 & 0,399 & 0,691 \\
\hline
\end{tabular}

Sumber : Data Penelitian, 2019

Berdasarkan Tabel 6 nilai koefesien jalur pengaruh profitabilitas (ROA) terhadap Return saham (RS) sebesar 0,054. Niloai koefesien jalur sebesar 0,054 menunjukan bahwakoefesien jalur profitabilitas (ROA) terhadap Return saham (RS) tidak sama dengan nol $(\mathrm{p} \neq 0)$. tabel 3 bawa nilai $t_{\text {hitung }}$ sebesar 0,399 sedangkan nilai dari $t_{\text {tabel }}$ dengan $(\mathrm{N}=145, \mathrm{k}=2$, $\mathrm{a}=0,05)$ diketahui sebesar 1,9766. Bedasarkan hasil uji $t_{\text {hitung }}$ dengan $t_{\text {tabe }} l$ diperoleh $t_{\text {hitung }}<$ nilai $t_{\text {tabel }}$ yaitu $0,399<$ 1,6554 signifikasi 0,691 < 0,05. Dapat dikatakan profitabilitas tidak memilki penngaruh terhaadap stock return pada perusahaaan perbaankan yang terdaptar di Burrs Efek Indonesia 2013-2017.

Bedasarkan hasil uji statistik tabel 4 signifikasi 0,000 $<0,05$ Sedangkan hasil uji $t_{\text {hitung }}$ dengan $t_{\text {tabel }}$ diperoleh $t_{\text {hitung }}>$ nilai $t_{\text {tabel }}$ yaitu 6,438 $>1,6554$ dengaan nilai signifikasi $0,00<0,05$. Dapatt disimpullkan bhwa intellectual capital memilki pengaruh positif pada perusahaaan pebankan yaang terdftar dii Brsa Effek Indonesia periode 2013-2017. Teori sumber daya menjelaska bahwa the company's yang memanfaatkan mengelola resource based intellectual karyawan perusahaan yang bagus dapat menggapai kelebihan bersaing dan value added. Atas dasar kelebihan bersaing dan value added meningkat makaa invesstor akan memberkan fee untuk karyawan perusahan denngan menanakan modal leebih tinggi, (Prastiwi \& Muna, 2014). Hasil peneelitian mendukung hasil penelitiajn yang dillakukan oleh (Prastiwi \& Muna, 2014), (Aprilia \& Isbanah, 2018), dan 
(Marlinda, 2018), intellectual capital memliki pengaaruh possitif terhdap profitabiilitas.

Bedasarkan hasl ujii statistik tabil 5 Hasil penelitian ini dengan nilain signifikansi sebesar 0,885 > 0,005 (5\%). Bedasarkan hasil uji thitung dan $t_{\text {tabel }}$ diperoleh $t_{\text {hitung }}<$ nilai $t_{\text {tabel }}$ yaitu $-0,145<1,6554$. Modal Intelektual (IC) tidak mnemiliki penagruh positif terhadap return saham. Berdasarkan signalling theory kandungan yang terdapat pada informasi perusahaan sangat dibutuhkan bagi investor dalam mengambil keputusan yang di digunakan untuk pengambilan keputusan yang diambil. Jika kandungan informasi atau sinya yang diberrikan perushaan buruk maka invesstor tidakan akan melkukan invstasi dana pada perusahaan, karna diakibatkan oleh bad news yang didapatkan dari perusahaaan. Peneltian ini mendukung penelitan yang dilakukan oleh (Aprilia \& Isbanah, 2018), dan (Marlinda, 2018) modal intelektual tidak memiliki pengaruh positif terhadap return saham, sebaliknya peneliitian ini tidak sejaalan engan penelitin yang diilakukan oleh (Prastiwi \& Muna, 2014) yamg mengaatakan bavwa modal intelektual memiliki pengaru positf terhdap return saham.

Bedasarkan Hasil uji statistik tabel 6 dengaan nilaii signifiikasi sebsar 0,691 > 0,05 nilai signifiikansi sebsar 0,691>0,005 (5\%). Bedasarkan hasil ujithitung dengan $t_{\text {tabe }}$ diperoleh $t_{\text {hitung }}<$ nilai $t_{\text {tabel }}$ yaitu $0,399<1,6554$ dengn niilai signifikasi 0,691 <0,05. Daapat disimplkan bawa profitabilitas tidakn memiliki pengaru tehadap return saham paada perusahaaan prbankan yang terdaftar di Bursaa Effek Indonesia perioode 2013-2017.

Analsis jalur dalaam penelitiian ini digunakan untuk membuktikan pengaruh intervening variabel profitabilitas pada hubungan modal intelektual dan return sahaml. Dapat disimpulkan bahwa profitabilitas tidak mampu memediasi hubungan secara tidak langsung. Hasil penelitian ini tidak selaras dengan penelitian yang dilakukan oleh (Prastiwi \& Muna, 2014) yang mengatakan bahwa profitabilitas mampu memediasi pengaruh intellectual capital terhadap return saham. Investor tidak memandang intellectual capital sebagai hal yang menyebabkan peningkatan harga saham. Investor lebih melihat analisis teknikal dalam memprediksi keuntungan investasi di pasar modal, dan investor juga lebih melihat issue-isue yang terjadi di pasar dalam mengambil keputusan dibandingan dengan melihat analisis fundamental.

\section{SIMPULAN}

Intelectual Capitall memliki pengaaruh possitif signiifikan terhdap profitabiilitas. Teori sumber daya mengatakan bahwa A Company yang bisa mengelola dan memanfaatkan resource based intelektual karyawan perusahaan yang bagus dapat meningkatkan keunggulan kompetitif dan value added. Meningkatnya keunggulan yaang dimliki oleh karyawan perusahaaan dapt meningkatkan valuue addded baagi perusahan tersebut sehingga invesstor akaaan senang untuk menanmkan kembali atau melaakukan invesstasi padaa perusahan tersebut agar mendapat keuntungan yang didapat dari penanaman saham pada perusahaan. Modal Intelektual tidak memliki pengaruh possitif terhaap stock return. Berdasaarkan teori sinyal, informasi yang terkandung di dalam sinyal tersebut dapat berupa postif dan negatif. Inforrmasi yaang didapat, dapaat menjdi sinnyal baggi para invesstor dalm mengambil kepuutusan yang akan diambiil. 
Jika Modal intelektual perusahaan baik atau meningkat mnaka return saham juga akan mkeningkat dan sebaliknya. Sehingga apabila inteletual tidak bagus maka return saham akan tidak memilki pengaruh terhadap return saham perusahaan. Modal intelektual dapaat digunnakan sbagai saranada dalm mengaambil perencaaan dan keputsan bagi investor. Profitablitas tidaak memliki pengarruh positif terhdap retern sahaam. Investor tidak memandang Profitability sebagai hal yang menyebbkan peniingkatan harrga saaham dalam mendapatkan stock return. Investor lebih cenderung melihat issue- issue yang terjadi di pasar modal secara langsung tanpa melihat analisis fundamental perusahaan tetapi investor lebih melihat analisis teknikal perusahaan dalam memprediksi advantage berivestasi di pasar modal. The Company dengan kondisi ROA yang meningkat dapat meningkatkan return saham perusahaan maka investor akan tertarik berinvestasi dalam menanamkan sahamnya. Modal Intelektual tidak memilki pengaruh positif terhadap stock return melalui Profitability Sebagai variable mediasi. Investor tidak memandang modal intelektual sebagai hal yang menyebabkan peningkatan harga saham. Investor lebih melihat analisis teknikal dalam memprediksi keuntungan investasi di pasar modal, dan investor juga lebih melihat issue-isue yang terjadi di pasar dalam mengambil keputusan dibandingan dengan melihat analisis fundamental.

Bebrapa ketrbatasan daan saraan dalaam peneltian iini, yag daaapat memberikan arah pada penelitian selanjutnya sebagai berikut:

Return saham dalam penelitian ini dijelaskan berdasarkan pengaruh variabele intellectual capital (VAIC) dan profitabilitas dengan R Square sebesar 0,018 atau 1,8. Sehingga variabel intellectual capital dan profitabilitas hanya mampu menjelaskan 1,8 dan sisanya 98,2 disebabkan faktor lain diluar penelitian. Ini mengindikasikan modal intelktual dan profitabilitas memiliki kemampuan yang sangat kecil dalam memprediksi return saham.

Berdasarkan kesimpulan peneliiti membrikan saaran bagii peneliti selanjtnya, yaiitu penliti selanjtnya daapat menammbah indiicator variable bebas seperti nilai perusahaan, kinerja keuangan, abnormal return dan variable mediasi. Serta penelitian selanjutnya objek penelitian pada paerusahaan manufaktur agar bisa melihat seberapa besar pengaruh terhadap variabel terikat. penelti juaga dapaat menelliti pengaaruh Modal intelektual bagii msa depann perusahan sebagaai tanbahan agarr dadpat menhasilkan penelitiian yaang lebbih baiik laggi. Dan perlu kajian terhadap variabel-variabel teknikal di pasar modal.

\section{REFERENSI}

Aprilia, D., \& Isbanah, Y. (2018). Pengaruh Intellectual Capital Terhadap Return Saham Melalui Kinerja Keuangan Pada Perusahaan Sektor Industri Barang Konsumsi Di Bei Tahun 2012-2017. Jurnal Ilmu Manajemen (Jim), 7(1).

Artha, D. R., Achsani, N. A., \& Sasongko, H. (2014). Analisis Fundamental, Teknikal Dan Makroekonomi Harga Saham Sektor Pertanian. Jurnal Manajemen Dan Kewirausahaan, 16(2). Https:/ / Doi.Org/10.9744/Jmk.16.2.175-184

Budiasih, I. G. A. N. (2015). Pengaruh Intellectual Capital Pada Kesehatan Keuangan Perusahaan Asuransi Jiwa Di Indonesia Fakultas Ekonomi Dan Bisnis Universitas Udayana ( Unud ), Bali , Indonesia Fakultas Ekonomi Dan 
Bisnis Universitas Udayana ( Unud ), Bali , Indonesia Salah Satu Ya. 13(2), 643-664.

Cheng, M., \& Christiawan, Y. J. (2011). Pengaruh Pengungkapan Corporate Social Responsibility Terhadap Abnormal Return. Jurnal Akuntansi Dan Keuangan, 13(1). Https:/ / Doi.Org/10.9744/Jak.13.1.24-36

Daniel, O.:, Studi, P., Manajemen, M., Ekonomi, F., Bisnis, D., Sam, U., \& Manado, R. (2015). Pengaruh Faktor Internal Terhadap Harga Saham Pada Perusahaan Lq 45 Yang Terdaftar Di Bursa Efek Indonesia The Effect Of Internal Factors On Stock Price Of The Company Lq 45 Listed On The Indonesian Stock Exchange (Idx). In Jurnal Emba (Vol. 863).

Ekawati Devi, B., \& Budiono, E. (N.D.). Pengaruh Intellectual Capital Terhadap Kinerja Keuangan Perusahaan (Studi Kasus Pada Perusahaan Elektronik, Otomotif Dan Komponen Yang Terdaftar Di Bursa Efek Indonesia (Bei) Periode 2011-2015).

Ghozali, I. (2011). Aplikasi Analisisis Multivariate Dengan Program Ibm Spss 19. Semaran.

Indrajaya, A. (N.D.). Pengaruh Modal Intelektual Terhadap Nilai Perusahaan Studi Empiris Di Perusahaan Manufaktur Yang Terdaftar Di Bursa Efek Indonesia Tahun 2011-2013 Skripsi Diajukan Untuk Memenuhi Salah Satu Syarat Memperoleh Gelar Sarjana Ekonomi Program Studi Akuntansi Oleh.

Jayanti, L. D., \& Binastuti, S. (2017). Pengaruh Intellectual Capital Terhadap Nilai Perusahaan Dengan Kinerja Keuangan Sebagai Variabel Intervening Pada Perusahaan Perbankan Yang Terdaftar Di Bursa Efek Indonesia. Jurnal Ilmiah Ekonomi Bisnis, 22(3).

Juwita, R., \& Angela, A. (2016). Pengaruh Intellectual Capital Terhadap Nilai Perusahaan Pada Perusahaan Indeks Kompas 100 Di Bursa Efek Indonesia. In Jurnal Akuntansi (Vol. 8).

Kartika, M., Saarce, D., \& Hatane, E. (N.D.). Pengaruh Intellectual Capital Pada Profitabilitas Perusahaan Perbankan Yang Terdaftar Di Bursa Efek Indonesia Pada Tahun 2007-2011.

Komang, N., \& Ariyani, S. (2018). Issn : 2302-8556 E-Jurnal Akuntansi Universitas Udayana Doi : Https://Doi.Org/10.24843/Eja.2018.V25.I01.P18 Pengaruh Modal Intelektual Pada Nilai Perusahaan Dengan Kinerja Keuangan Sebagai Variabel Mediasi Fakultas Ekonomi Dan Bisnis Universitas Udayana (. 25, 464-496.

Kusdarmawan, P. A. (2018). Analisis Abnormal Return Saham Sebelum Dan Sesudah Reverse Stock Split Pada Perusahaan Di Bei Periode 2011- Fakultas Ekonomi Dan Bisnis Universitas Udayana ( Unud ), Bali , Indonesia Return Saham Yang Positif Menyebabkan Investor Tertarik Dan Berminat Men. 00(00), 1-29.

Lestari, N., \& Candra Sapitri, R. (2016). Pengaruh Intellectual Capital Terhadap Nilai Perusahaan. 4(1), 28.

Marlinda, Y. (2018). Pengaruh Intellectual Capital Dan Struktur Modal Terhadap Return Saham Dengan Kinerja Keuangan Sebagai Variabel Intervening (Studi Pada Perusahaan Yang Terdaftar Pada Jii (Jakarta Islamic Index) Periode 2012-2016). El Muhasaba: Jurnal Akuntansi, 1(1), 93. Https:/ / Doi.Org/10.18860/Em.V1i1.5411 
Masni, F. (2013). The Influence Of Performance Valuation Using Return On Investment, Earning Per Share, Price Earning Ratio And Return On Equity On Stock Of Return (Study On Banking Corporation Listed In Indonesia Stock Exchange). Retrieved From Www.Portalreksadana.Com

Mayfi, F., \& Rudianto, D. (2014). Mayfi Dan Rudianto 348-362 Jurnal Mix.

Nharaswarie, P., Dwija Putri, A., \& Astika, P. (N.D.). Pengaruh Intellectual Capital Pada Abnormal Return Saham Yang Diintervening Oleh Kinerja Keuangan (Studi Empiris Pada Perusahaan Asuransi Di Bei).

Prastiwi, A., \& Muna, N. (2014). Pengaruh Intellectual Capital Terhadap Return Saham Melalui Kinerja Keuangan Pada Perusahaan Real Estate Dan Properti Yang Terdaftar Di Bursa Efek Indonesia (Bei) Tahun 2010-2012. Diponegoro Journal Of Accounting, 3(2), 1-15.

Stewart, T. A. (1991, June). Brainpower: How Intellectual Capital Is Becoming America's Most Valuable Asset,. Fortune, 40-46.

Stewart, T. A. (1994, October). Your Company's Most Valuable Asset: Intellectual Capital. Fortune, 68-74.

Sugiyono. (2012). Metode Penelitiankualitatif Kuantitatif Dan R\& D. Bandung: Alfabeta.

Sukiati, W., Nuryani, N., \& Leviany, T. (2015). Pengaruh Modal Intelektual, Kinerja Keuangan, Investasi Pada Riset Dan Pengembangan Terhadap Nilai Perusahaan (Pada Perusahaan Manufaktur Yang Terdaftar Di Bei). Jurnal Aset (Akuntansi Riset), 7(2), 29. Https://Doi.Org/10.17509/Jaset.V7i2.8860

Ulum, I. (2013). Model Pengukuran Kinerja Intellectual Capital Dengan Ib-Vaic $\begin{array}{llll}\text { Di Perbankan } \quad \text { Syariah. } & \text { Inferensi, }\end{array}$ Https:/ / Doi.Org/10.18326/Infsl3.V7i1.185-206

Wato, T. (2017). Pengaruh Modal Intelektual Terhadap Manajemen Laba Riil Dan Future Stock Returns. Media Riset Akuntansi, Auditing Dan Informasi, 16(2), 107. Https://Doi.Org/10.25105/Mraai.V16i2.1640

Wijayani, D. R. (2017). Pengaruh Intellectual Capital Terhadap Kinerja Keuangan Perusahaan Publik Di Indonesia (Studi Empiris Pada Perusahaan Manufaktur Di Bei 2012-2014). Jurnal Riset Akuntansi Dan Bisnis Airlangga, 2(1). Https://Doi.Org/10.31093/Jraba.V2i1.23 